This is the final peer-reviewed accepted manuscript of:

Nannoni E., Liuzzo G., Serraino A., Giacometti F., Martelli G., Sardi L., Vitali M.,

Romagnoli L., Moscardini E., Ostanello F., 2017. Evaluation of pre-slaughtering losses of Italian heavy pigs. Animal Production Science 57(10): 2072-2081

The final published version is available online at: https://doi.org/10.1071/AN15893 
Publisher: CSIRO; Journal: AN:Animal Production Science

Article Type: research-article; Volume: ; Issue: ; Article ID: AN15893

DOI: 10.1071/AN15893; TOC Head:

AN15893

E. Nannoni et al.

Pre-slaughter losses of heavy pigs

\section{Evaluation of pre-slaughter losses of Italian heavy pigs}

Eleonora Nannoni $^{\mathrm{A}, \mathrm{C}}$, Gaetano Liuzzo ${ }^{\mathrm{B}}$, Andrea Serraino ${ }^{\mathrm{A}}$, Federica Giacometti ${ }^{\mathrm{A}}$, Giovanna

Martelli $^{\mathrm{A}}$, Luca Sardi ${ }^{\mathrm{A}}$, Marika Vitali $^{\mathrm{A}}$, Lucia Romagnoli ${ }^{\mathrm{B}}$, Eros Moscardini $^{\mathrm{B}}$ and Fabio

Ostanello ${ }^{\mathrm{A}}$

${ }^{\mathrm{A}}$ Department of Veterinary Medical Sciences, University of Bologna, Via Tolara di Sopra 50, 40064, Ozzano Emilia, Italy.

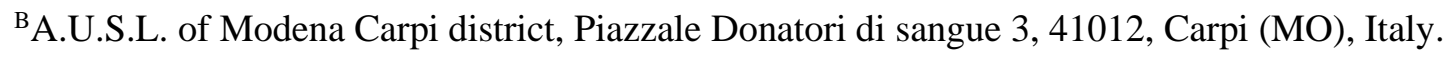

${ }^{\mathrm{C}}$ Corresponding author. Email: eleonora.nannoni2@unibo.it

A retrospective observational study evaluated the risk factors for pre-slaughter losses (i.e. animal deaths occurring during transport and lairage) and their economic impact in Italian heavy pigs ( $160 \mathrm{~kg}$ bodyweight). Of the 3344730 pigs transported, 1780 (0.053\%) died before slaughter, with most losses occurring during transport (56.6\%). The estimated economic impact was of $424000 €$. The percentage of batches with at least one animal lost pre-slaughter increased during summer $(P<0.001)$. The proportion of pre-slaughter losses was higher when journey lasted more than $90 \mathrm{~min}(P<0.001)$ and was positively correlated with transport duration $(P<0.01)$. Losses were higher $(P<0.01)$ in batches transported at low stocking densities (i.e. when heavier pigs were transported). Batches with lower slaughtering order (i.e. longer lairage time) had higher proportions of losses $(P<0.001)$. Logistic regression analysis showed that the odds of a given batch to have at least one animal lost pre-slaughter were 1.32 times higher for batches slaughtered in summer, 1.54 times higher if journey durations exceeded $90 \mathrm{~min}, 1.25$ times higher for batches with low slaughtering order, and not significantly influenced by stocking density during transport.

Additional keywords: economic impact, pig welfare, transport.

The identification of critical points during transport and slaughtering procedures may significantly improve animal welfare during transport. In heavy pigs, long travel duration, low stocking density and overnight lairage resulted in increased animal losses. The routine collection and analysis of animal-loss data at slaughterhouses could reduce the economic impact of animal losses and be of help in improving future legislation on the protection of pigs during transport.

\section{Introduction}

Transporting pigs to slaughter raises concerns principally from two points of view, namely, the welfare of the transported livestock, and the economic impact for the industry (Averós $e t$ 
Publisher: CSIRO; Journal: AN:Animal Production Science

Article Type: research-article; Volume: ; Issue: ; Article ID: AN15893

DOI: 10.1071/AN15893; TOC Head:

al. 2008). Animal losses (i.e. animal deaths occurring during transport and lairage) are a multifactorial problem involving genetics, management, handling, facilities and truck design, and processing plant and environmental factors. Ritter et al. (2009) defined animal losses as 'pigs that die or become non-ambulatory at any stage of the marketing process, defined as movement from the grower-finisher environment to stunning at the abattoir'. Continued research efforts are needed to understand how each factor can affect animal welfare (Ritter $e t$ al. 2009) and, therefore, animal losses. Differences among continents and countries may include transportation times and distances, feed and water intervals (due to regulatory differences), road condition, trailer design, animal genetics and extreme weather conditions (Schwartzkopf-Genswein et al. 2012). All these variables add complexity to the individuation of deficiencies within the pre-slaughter logistic chain, since each of them, as well as their interaction, can considerably affect animal welfare and animal losses during transport (Carr et al. 2008; Miranda-de la Lama et al. 2014). However, despite differences, general principles are consistent among studies. Seasonality of pig losses during transport has been extensively studied in summer and in winter (Schwartzkopf-Genswein et al. 2012), and it is well known that transportation losses tend to be higher at warm environmental temperatures and that the welfare of pigs transported on the lower deck and in front compartments can be particularly compromised (Christensen and Barton-Gade 1999; Brown et al. 2011). Pig welfare may benefit from transportation at reduced loading densities (Ritter et al. 2007; Gerritzen et al. 2013), although the effect of stocking density on animal losses is less consistent in the literature (Barton Gade et al. 2007). Last, pre-slaughter losses can also occur at the slaughter plant, as a consequence of stressful (or uncontrolled) lairage conditions, such as unfamiliar environment, fasting and regrouping (Warriss 2003; Brandt and Aaslyng 2015).

In Italy, the typical slaughtering weight of pigs is considerably higher than in other countries, since the production of protected designation of origin (PDO) hams, such as Parma ham, requires the attainment of at least $160 \mathrm{~kg}$ of body weight (BW; Consortium for Parma Ham 1992). It has been suggested that losses during transport could be greater in heavier pigs (>100 kg BW), since they might show a greater metabolic response and increase in rectal temperature when handled and transported (Ellis and Ritter 2005). Greater losses in heavy pigs may also be related to a lack of respect for appropriate space allowance in the truck, especially given the absence of specific legislative requirements for pigs above $100 \mathrm{~kg} \mathrm{BW}$ (EC 2005).

To the best of our knowledge, only very recently a study analysed the factors associated with mortality of heavy pigs during transport and lairage (Vitali et al. 2014). However, conversely to the present study, the mentioned research did not estimate the economic impact of pre-slaughter losses, and did not take into account stocking density during transport. 
Publisher: CSIRO; Journal: AN:Animal Production Science

Article Type: research-article; Volume: ; Issue: ; Article ID: AN15893

DOI: 10.1071/AN15893; TOC Head:

The present survey followed the case study of a single Italian abattoir, collecting retrospective data on the batches shipped to the abattoir over almost 5 years, so as to

(1) describe and analyse the amount and causes of pre-slaughter animal losses (i.e. losses occurring during transport and lairage);

(2) analyse the risk factors associated with pre-slaughter animal losses (season, transport duration, stocking density, slaughtering order); and

(3) assess the economic impact of animal losses.

All data were retrieved from the Public Veterinary Service database filled by the veterinarians performing meat inspections at the surveyed plant. The routine records of causes for pig and carcass condemnations at slaughterhouses can, in fact, constitute a database for studies regarding animal welfare, swine diseases and conditions responsible for economic losses due to total or partial carcass and offal condemnations. Nevertheless, the literature available regarding the causes of carcass condemnations in pigs is scarce (Garcia-Diez and Coelho 2014). The aim of the present study was to partially fill this knowledge gap on preslaughter animal losses by elaborating data collected under current commercial conditions.

\section{Materials and methods}

\section{Data collection}

The survey was conducted in a slaughterhouse located in the Emilia-Romagna Region, northern Italy. The company owing the plant is a leader in slaughtering and processing pig meat. The activities of the company include the entire productive chain (slaughtering, deboning, primal cuts) and its products are sold both on national and international markets, mainly to food industries and large retail chains. The plant where the study was conducted presently slaughters more than 780000 pigs per year; these pigs are almost entirely heavy pigs (i.e. slaughtered at $160 \mathrm{~kg}$ or higher $\mathrm{BW}$ and at a minimum age of 9 months) intended for PDO Parma ham production (Consortium for Parma Ham 1992), at a line speed of $\sim 450$ pigs per hour.

The survey was conducted as a retrospective observational study, and it was performed by analysing the database of the local Public Veterinary Services (Azienda Unità Sanitaria Locale di Modena), whose veterinarians conducted meat inspections in the surveyed plant. Data collection refers to the period between 10 April 2009 and 31 December 2013 ( 57 months of activity).

The following data were retrieved from the database for each slaughtering batch (pigs from the same pig unit transported to the slaughterhouse on the same day), so as to evaluate their relationships with pre-slaughter losses occurred during transport and lairage: 
Publisher: CSIRO; Journal: AN:Animal Production Science

Article Type: research-article; Volume: ; Issue: ; Article ID: AN15893

DOI: 10.1071/AN15893; TOC Head:

- geographic provenance (province and region) of the batches, as obtained from the authorisation code of each farm;

- journey duration: an estimate was obtained using a common web-based application (www.viamichelin.it, last accessed December 15, 2015) to calculate the time required to travel from the municipality of the farm to the municipality of the slaughterhouse; although the calculated journey duration does not take into account the exact distance from farm or possible delays due to accidents occurred during the journey, still, this travel duration has been used because it allowed to standardise travel duration based on the geographic location of the farm;

- day of the week and month when the slaughter took place;

- number of pigs per batch (obtained by adding the number of carcasses actually inspected to the number of animals lost pre-slaughter);

- slaughtering order, which was the number attributed to every batch on arrival; lower values correspond to pigs that reached the slaughterhouse on the day before slaughtering, spending the night in lairage and being the first slaughtered on the day after their arrival.

During unloading at the slaughterhouse, veterinarians inspected the health status of the pigs and the characteristics of the vehicles to assess transport conditions (e.g. stocking density), so as to evaluate compliance with the European regulation concerning the transport of slaughter pigs (EC 2005).

Due to the study design, some factors related to transport (truck driver, number of truck stops, truck design, average temperature during transport) or lairage (lairage duration, and stocking density for each batch) could not be taken into account. The trucks used by the abattoir in the large majority of transports were three-deck type, having an overall internal area of $\sim 49.6 \mathrm{~m}^{2}$. Transport could be carried out with the tractor+trailer alone (semi-trailer truck, commonly loading $~ 70$ pigs) or with the addition of a second trailer (overall load: 140 pigs). The number of pigs that could be loaded on the truck was calculated at loading on the basis of the average BW of the batch, so as to comply with the stocking density during transport prescribed by law $\left(235 \mathrm{~kg} / \mathrm{m}^{2}\right.$ maximum, EC 2005$)$.

At the slaughterhouse, animals were kept in lairage pens on slatted floors. To ensure that different batches are not mixed, the slaughterhouse has 20 large pens that can be divided into eight sections each. Every section can contain 15 pigs, and is equipped with a drinker and a water sprinkler. 
Publisher: CSIRO; Journal: AN:Animal Production Science

Article Type: research-article; Volume: ; Issue: ; Article ID: AN15893

DOI: 10.1071/AN15893; TOC Head:

\section{Statistical analyses}

Data were preliminary analysed using descriptive statistics, so as to study the main productive indicators of the plant (e.g. number of pigs introduced, season of the year, geographic provenance, average batch size, pre-slaughter losses) both as absolute values and in relation to independent variables (e.g. year, season, day of the week).

Transport could be undertaken with the tractor+trailer alone (semi-trailer truck) or with the addition of a second trailer. To account for this difference, the subsequent statistical analysis was conducted after dichotomising stocking density during transport according to the number of animals. The median was calculated for each category (71 and 140 pigs respectively). This method allowed the identification of batches of 'high density during transport', i.e. all batches of more than 71 pigs transported by the same trailer or all batches of more than 140 pigs (in this case a second trailer was used).

Risk factors correlated with the increase in the probability that a given batch has at least one animal lost pre-slaughter were identified using a two-stage analysis.

In the first stage, the proportion of batches with at least one animal lost pre-slaughter (during transport and lairage) was evaluated according to different possible risk factors using the chi-square test. The evaluated factors were season (winter period, from October to March; summer period, from April to September), journey duration, slaughtering order and stocking density. Continuous variables were divided into two categories on the basis of the median value; the two categories for travel duration were either less or more than $90 \mathrm{~min}$, and for slaughtering order were either $1 \div 11$ or $\geq 12$.

In the second stage of the statistical analysis, so as to estimate the influence of risk factors on the probability for the batches to have at least one animal lost pre-slaughter, factors with $P$ $<0.15$ were evaluated using a binary logistic model. The model was based on the simultaneous entry of all variables (season, journey duration, slaughtering order and density during transport), and its efficacy was assessed on the basis of the likelihood-ratio and the Hosmer-Lemeshow statistic. The odds ratio (OR) and 95\% confidence intervals (95\% CI) were calculated from the final binary logistic model.

Kolmogorov-Smirnov test for goodness of adaptation was used to verify distribution normality. On the basis of the results of Kolmogorov-Smirnov test (all variables were not normally distributed), Mann-Whitney $U$ or Kruskal-Wallis $\mathrm{H}$ test were used to compare quantitative data.

All statistical analyses were performed using the software IBM SPSS version 21 (IBM Corp., Armonk, NY). 
Publisher: CSIRO; Journal: AN:Animal Production Science

Article Type: research-article; Volume: ; Issue: ; Article ID: AN15893

DOI: 10.1071/AN15893; TOC Head:

\section{Results}

Animals and their origin

In the period of the survey, 26635 pig batches were slaughtered over 1059 working days (on average 25 batches/day), for a total of 3344730 pigs (3158 per day on average).

Batches came from 1896 farms, even if 50\% of the batches came from only 88 farms.

Overall, the average number of pigs slaughtered monthly was close to 60000 , with comparable trends between the years considered in the survey. Reduced volumes were recorded in April 2009 ( $-28 \%$, due to the fact that data were available only from the second week of the month) and in June 2010 ( $-34 \%$, due to a workers' union controversy that involved the abattoir).

The number of pigs introduced per week day is constant across the week, with the exception of Thursdays, when, due to internal organisation reasons, the abattoir works for fewer hours per day and, therefore, the number of pigs slaughtered is lowered to $30-40 \%$ if compared with the full days.

The animals received by the slaughterhouse during the 5 years of the survey came for most part (88.9\% of pigs and $89.4 \%$ of batches) from Emilia-Romagna or from nearby northern Italian regions (Piedmont and Lombardy), within a radius of $\sim 250 \mathrm{~km}$ from the slaughterhouse.

\section{Animal losses and the estimate of the economic impact}

During the survey, a total of 1780 pigs $(0.053 \%$ of the pigs transported to the plant) died before slaughter. At the average BW of $160 \mathrm{~kg}$, the overall weigh of the pre-slaughter losses equals to $284800 \mathrm{~kg}$. Of the carcasses, 1834 (corresponding to $51 \%$ of total animal losses) were judged not suitable for human consumption (i.e. condemned). Total animal losses (preand post-slaughter) accounted for 3614 animals and carcasses, of which 51\% were carcass condemnations.

Commodity exchange quotations in the province of the abattoir (http://borsamercimodena.it, last accessed December 15, 2015) for slaughtering pigs weighing between 160 and $176 \mathrm{~kg}$ showed in the period of the survey prices that varied between a minimum of 1.26 and a maximum of $1.76 € / \mathrm{kg} \mathrm{BW}$, with an average price of $1.49 €$ in the last year of the survey (2013). The economic impact of pre-slaughter losses in the entire period can be estimated at about $424000 €$, corresponding to $0.053 \%$ of the profit arising from slaughtering during the period of the survey. Moreover, this figure does not take into account 
Publisher: CSIRO; Journal: AN:Animal Production Science

Article Type: research-article; Volume: ; Issue: ; Article ID: AN15893

DOI: 10.1071/AN15893; TOC Head:

the loss of profit arising from the fact that a significant portion of meat is intended for highvalue cured-ham production.

\section{Pre-slaughter losses}

In 1523 of the 26635 batches that were slaughtered during the survey (5.7\%), at least one pig had been lost pre-slaughter (i.e. either found dead or killed); within this category, only in $10.1 \%$ of the batches, the number of pigs lost was $\geq 2$ (Fig. 1). In one single case, occurring in 2012, 32 pigs were found dead on the truck on arrival as a consequence of severe negligence by the transporter. The reason for pre-slaughter losses was known for 1364 of the 1780 pigs lost $(76.6 \%)$. Losses occurred mostly during transport (56.6\% of the animals lost preslaughter were found dead at unloading) and during lairage (39.1\% of the losses occurred in lairage pens), whereas only a small percentage of pigs was euthanized (1.7\%). For $\sim 3 \%$ of losses, it has not been possible to discriminate whether the animal death occurred during transport or lairage, and animal losses were generically attributed to 'truck and lairage'.

Figure 2 shows the distribution across the months of pre-slaughter losses that occurred during the whole survey and by year. The percentage of pre-slaughter animal losses showed a seasonal variation, with an increase during the warmer months (between June and September). So as to verify the hypothesis that pre-slaughter losses could depend on season (and therefore on environmental and truck internal temperatures), the proportion of batches with at least one animal lost pre-slaughter was evaluated in relation to the period of the year $($ summer $=$ from April to September; winter $=$ from October to March; see Table 1). Results indicated that there was a statistically significant increase $(+1.6 \%)$ in the percentage of batches with at least one animal lost during summer when compared with winter $\left(\chi^{2}=28.27\right.$, $P<0.001)$. Similar results could be obtained if the variable taken into account was the number of animals lost pre-slaughter per batch or the number of animals lost pre-slaughter per number of animals received by the abattoir per batch (Table 2). Differences were statistically significant also in this case (Mann-Whitney $U=87232898, P<0.001$; and Mann-Whitney $U=87235611, P<0.001$ ), with an increase in animal losses during the warmer months.

Figure 3 further confirms the seasonal variations, but also shows different trends in the years considered. More accurately, the seasonal difference in the percentage of batches with at least one animal lost pre-slaughter was significant $(P<0.05)$ in years 2010, 2011 and 2013, but was not significant in 2009 and in 2012.

No difference $(P>0.05)$ was detected (data not shown) concerning the distribution of preslaughter animal losses on a week-day basis. 
Publisher: CSIRO; Journal: AN:Animal Production Science

Article Type: research-article; Volume: ; Issue: ; Article ID: AN15893

DOI: 10.1071/AN15893; TOC Head:

The relationship between pre-slaughter animal losses and transport duration was also studied. Journey duration was estimated as described in the Materials and methods section. The percentage of animals lost pre-slaughter of the total number of animals received by the abattoir (data per batch) was significantly $(P<0.01)$ correlated with transport duration (nonparametric Sperman correlation coefficient $=0.070$ ). Similar results were found when the winter and summer periods were considered separately.

So as to allow a further comprehension of the relationship between the two parameters, the mean of animals lost pre-slaughter per batch and the rate of animals lost pre-slaughter per batch (i.e. the number of animals lost pre-slaughter per number animals received by the abattoir per batch) were calculated depending on journey duration; two categories were set according to the median journey duration, namely, less than or more than $90 \mathrm{~min}$ (Table 2). The mean of animals lost pre-slaughter per batch and the rate of animals lost pre-slaughter per batch were significantly higher (Mann-Whitney $U=86448609, P<0.001$; and MannWhitney $U=86411823, P<0.001$, respectively) when journey lasted more than $90 \mathrm{~min}$.

Table 1 shows the batches with at least one animal lost pre-slaughter by journey duration. Batches that were transported for longer than $90 \mathrm{~min}$ had a significantly increased probability $\left(\chi^{2}=74.16, P<0.001\right)$ of having at least one animal lost pre-slaughter.

The relationship between animal losses and the slaughtering order of batches was analysed. Since the slaughtering order depends on the order of arrival at the slaughterplant, the aim of the analysis was to understand whether longer lairage is associated with increased preslaughter losses. The batches with lower slaughtering order $(<12$, i.e. those subjected to longer lairage times, since they arrived at the abattoir during the night before slaughtering) had significantly higher proportions of animal losses $\left(\chi^{2}=23.67, P<0.001\right.$, see Table 1$)$. Similar results were obtained if the variable taken into account was the mean of animals lost pre-slaughter per batch or the rate of animals lost pre-slaughter per batch (Table 2). Differences were statistically significant also in this case (Mann-Whitney $U=87225794, P<$ 0.001; and Mann-Whitney $U=87226022, P<0.001$, respectively), with an increase in animal losses if slaughtering order was $\geq 12$.

Results concerning pre-slaughter losses in relation to stocking density during transport are shown in Tables 1 and 2. Unexpectedly, the percentage of batches with at least one animal lost pre-slaughter was significantly higher in animals that were transported at lower stocking densities $\left(\chi^{2}=7.59 ; P<0.01\right)$. The analysis of quantitative data (mean of animals lost preslaughter per batch or the rate of animals lost pre-slaughter per batch) confirmed significantly increased losses (Mann-Whitney $U=87976426, P<0.01$; and Mann-Whitney $U=$ 
Publisher: CSIRO; Journal: AN:Animal Production Science

Article Type: research-article; Volume: ; Issue: ; Article ID: AN15893

DOI: 10.1071/AN15893; TOC Head:

$87782870, P<0.001$, respectively) in batches transported at lower stocking densities (Table 2).

The results of the logistic regression analysis are reported in Table 3. The odds of a given batch to show at least one animal loss pre-slaughter were 1.32 times higher for batches slaughtered in summer season, 1.54 times higher if journey durations exceeded 90 min and 1.25 times higher for batches with a lower slaughtering order. The odds of a given batch to show at least one animal lost pre-slaughter was not significantly influenced by the stocking density.

\section{Discussion}

\section{Pre-slaughter losses}

During the survey, the yearly percentage of animal losses pre-slaughter varied between $0.042 \%$ and $0.070 \%$. Such a value is considerably lower than the data collected in NorthAmerican studies, and lower than what has been observed in many European countries (as reviewed by Ritter et al. 2009). However, the percentage is in agreement with a recent Italian study (Vitali et al. 2014). If we exclude the incomplete data from Year 2009, overall preslaughter losses were consistent throughout the years of the survey and, on average, accounted for $0.050 \%$ of the animals received by the abattoir, varying between a minimum of $0.042 \%$ (302 pigs) in 2013 and a maximum of $0.056 \%$ (377 pigs) in 2010.

Losses occurred mostly during transport (animals found dead at unloading) and during lairage (animals found dead between unloading and slaughtering), whereas only a small number of pigs was euthanized by a veterinarian. It is worth noting that, although preslaughter handling (i.e. loading, transport and unloading) is recognised as one of the strongest stressor in a pig's life (Pérez et al. 2002; García-Celdrán et al. 2012), also lairage (especially when aggressions due to mixing occur) may raise considerable welfare concerns (Geverink et al. 1996; Brandt and Aaslyng 2015). A certain degree of contradiction exists among studies about the definition of optimal lairage duration (Salmi et al. 2012). Nevertheless, it is well known that inadequate treatment during lairage (e.g. group mixing, water and food deprivation, lack of environmental control, poor handling) may result in additional stress, and increase economic losses due to deaths, skin damage and poor meat quality (Pérez et al. 2002; Warriss 2003). Although in our study lairage conditions were not monitored, an increase in pre-slaughter losses was observed when pigs stayed overnight in lairage pens, which could indicate the existence of uncontrolled conditions that may have increased animal losses.

A strong relationship was found between season of the year and pre-slaughter losses, with an increase in losses during the summer months. The seasonal difference in the percentage of batches with at least one animal lost pre-slaughter was significant in years 2010, 2011 and 
Publisher: CSIRO; Journal: AN:Animal Production Science

Article Type: research-article; Volume: ; Issue: ; Article ID: AN15893

DOI: 10.1071/AN15893; TOC Head:

2013, but not significant in 2009 and in 2012. However, it should be considered that data for the year 2009 were incomplete, since they were collected only from the month of April onward and this excluded data collection from the cold months of January and February, limiting the effect of the cold season on the total losses. The increase in animal losses during the warmer months is in agreement with the literature, since many authors observed how hot temperatures, especially when combined with high relative humidity, impair the dissipation of body heat in pigs, increasing physical exhaustion and animal losses (Warriss and Brown 1994; Abbott et al. 1995; Barton Gade et al. 2007; Haley et al. 2008b; SchwartzkopfGenswein et al. 2012; Nannoni et al. 2014; Vitali et al. 2014). In agreement with the cited literature, pre-slaughter losses reached a maximum in the month of August in our study. A further confirmation of the trend can be found if the yearly averages are considered in relation to the historical weather data for the geographic area of the slaughterhouse. In fact, average pre-slaughter losses reached $0.061 \%$ in the month of June, $0.070 \%$ in July and $0.082 \%$ in August. In July 2010, pre-slaughter losses peaked at $0.097 \%$. Historical weather reports show that the summer of years 2009, 2011 and 2013 were characterised by particularly high temperatures (during summer, the following temperatures were recorded in the area of the slaughterhouse: in 2009 , average $21.1^{\circ} \mathrm{C}$, range $34.6-9.25^{\circ} \mathrm{C}$; in 2010 , average $19.8^{\circ} \mathrm{C}$, range $32.7-7.4^{\circ} \mathrm{C}$; in 2011 , average $20.8^{\circ} \mathrm{C}$, range $34.1-7.8^{\circ} \mathrm{C}$; in 2012 , average $20.6^{\circ} \mathrm{C}$, range $34,4-7.1^{\circ} \mathrm{C}$; in 2013 , average $19.9^{\circ} \mathrm{C}$, range $33.4-7.9^{\circ} \mathrm{C}$; SCIA 2015), and these observations are in good agreement with the fact that, in 2011 and 2013, a significant increase in preslaughter losses during summer has been observed. In regard to year 2010, data show that July 2010 was one of the hottest months recorded in northern Italy (the mean temperature in the geographic area of the slaughterhouse exceeded the historical average temperature by $2.74^{\circ} \mathrm{C}$, with the average of $25.3^{\circ} \mathrm{C}$, range $37.2-12.9^{\circ} \mathrm{C}$; SCIA 2015). Furthermore, in year 2010 (i.e. when the highest pre-slaughter losses were recorded), abundant precipitations were recorded in northern Italy, and the subsequently high relative humidity may have increased the discomfort experienced by animals transported in the hot season. Although information available on the effects of humidity at different temperatures on pig behaviour is scarce, according to Huynh et al. (2005), high humidity accentuates the effects of temperature on pig behaviour. Schrama et al. (1996) also observed that the combination of high temperature and high humidity reduces the ability of pigs to dissipate body heat effectively through radiative, convective or evaporative means.

However, it is worth noting that climatic factors may play differently across countries and that, for example, studies conducted in North America have highlighted increased transport losses during winter and autumn (Ritter et al. 2008; Sutherland et al. 2009). 
Publisher: CSIRO; Journal: AN:Animal Production Science

Article Type: research-article; Volume: ; Issue: ; Article ID: AN15893

DOI: 10.1071/AN15893; TOC Head:

In the present study, prolonged journey durations (i.e. exceeding $90 \mathrm{~min}$ ) resulted in greater pre-slaughter losses. This finding is in agreement with what is described in the literature.

Gosálvez et al. (2006) observed that mortality and weight losses increased as distance increased, and found the more marked effects in journeys greater than $100 \mathrm{~km}$. Similarly, Sutherland et al. (2009) found an increase in mortality when journey duration increased from $30 \mathrm{~min}$ to $4 \mathrm{~h}$. However, it is worth noting that, according to Werner et al. (2007), if initial stress were reduced by good loading practices, subsequent stress during transport would be reduced as well. In their study, Werner et al. (2007) observed increased mortality rates both during very long $(>8 \mathrm{~h})$ and in very short $(<1 \mathrm{~h})$ transports, and suggested that during journeys between 1 and $8 \mathrm{~h}$, animals may have time to recover from loading, whereas during longer journeys (more than $8 \mathrm{~h}$ ), other factors (water and food deprivation, balancing movements, vibrations, temperature extremes) may compromise animal welfare, resulting in increased mortality rates.

The well known relationship between journey duration and pre-slaughter losses raises specific concerns in countries, such as Italy, where, in the past decades, pig slaughtering has gradually concentrated in a smaller number of large plants, likely resulting in longer average trip durations. This aspect should be kept in consideration for the development of future animal protection policies.

When regarding stocking density during transport, it is worth remembering that, in North America, some national and provincial guidelines take into account environmental temperature variation together with slaughter weight, although there is no firm agreement on how much loading densities should be reduced at warmer temperatures (SchwartzkopfGenswein et al. 2012). At present, no similar guideline is available in Italy where, on the basis of European legislation (EC 2005), the loading density for pigs of $\sim 100 \mathrm{~kg}$ should not exceed $235 \mathrm{~kg} / \mathrm{m}^{2}$. For pigs of $160-\mathrm{kg} \mathrm{BW}$, this provision results in a stocking density of 0.681 pigs $/ \mathrm{m}^{2}$. However, it is acknowledged that an increase up to $20 \%$ of the minimum required surface area may be needed depending on the meteorological conditions and the journey time (EC 2005). In the present survey, loading density has been retrospectively defined as 'high' or 'low' on the basis of the number of pigs transported and the type of the truck. With this simple dichotomy, a reduction in pre-slaughter animal losses was observed at high loading densities. Such a result is in contrast with the literature, since most authors have found a positive correlation between stocking density and animal losses (Barton Gade et al. 2007; Ritter et al. 2007; Fitzgerald et al. 2009; Pilcher et al. 2011). However, the aforementioned studies were conducted on pigs whose average BW did not exceed $130 \mathrm{~kg}$, i.e. they were considerably lighter if compared with those involved in the present study. Conversely, Haley et al. (2008a) failed to find such a correlation when data were adjusted for temperature. It is 
Publisher: CSIRO; Journal: AN:Animal Production Science

Article Type: research-article; Volume: ; Issue: ; Article ID: AN15893

DOI: 10.1071/AN15893; TOC Head:

also worth noting that, according to Ritter et al. (2007), in pigs of $130-\mathrm{kg} \mathrm{BW}$, increased

space allowance during transport resulted in reduced mortality only up to a certain threshold

(i.e. $0.462 \mathrm{~m}^{2} / \mathrm{pig}$ ), and no additional effect was observed when space allowance was further increased (0.489 and $\left.0.520 \mathrm{~m}^{2} / \mathrm{pig}\right)$.

To the best of our knowledge, the relationship between loading density and transport losses in heavier pigs has never been investigated, and the only study dealing with transport losses in heavy pigs (Vitali et al. 2014) did not distinguish between the effect relative to stocking density during transport and during lairage. There is some evidence in the literature that providing pigs with too much space during transport to slaughter may have negative effects on welfare and meat quality, due to the fact that the animals can be thrown around and get struck and bruised as a result of unexpected movements of the lorry (Barton Gade and Christensen 1998). Moreover, if pigs can move around, they may be involved in confrontation and fights and this can cause muscular fatigue and glycogen depletion, making them prone to dark, firm, dry meat (Guàrdia et al. 2005). However, it is worth noting that, due to the fact that loading conditions were not surveyed in the present study, some confounding effects may have occurred. For example, in the present study, loading density was defined retrospectively on the basis of the number of pigs loaded on each truck. For this reason, low loading densities were recorded when fewer pigs were transported on a truck, regardless of their BW.

Considering that pigs intended for Parma ham are generally slaughtered at a BW ranging from $155 \mathrm{~kg}$ to $176 \mathrm{~kg}$, and that the stocking density required by law is expressed in $\mathrm{kg} / \mathrm{m}^{2}$, it is reasonable to expect that low-density transports may have involved heavier pigs, which are more susceptible to excessive metabolic responses when handled and transported (Ellis and Ritter 2005). However, it should be considered that the logistic regression analysis does not show a significantly increased risk of having at least one animal loss pre-slaughter due to the different stocking density.

\section{Economic impact}

In the present study, the economic impact of pre-slaughter losses was estimated on the basis of the number of carcasses that were condemned (i.e. on the kilograms of meat that was condemned and not used for human consumption), and amounted to $0.053 \%$ of the income arising from pig slaughtering. In other words, the value of pre-slaughter losses accounts for $0.13 €$ for each pig slaughtered. Considering a mean of 3158 animals slaughtered per day, the daily loss would be about $400 €$. This value can represent a parameter for evaluating the costeffectiveness of some interventions to reduce losses pre-slaughter (e.g. improvement of transport, reduction of lairage time). 
Publisher: CSIRO; Journal: AN:Animal Production Science

Article Type: research-article; Volume: ; Issue: ; Article ID: AN15893

DOI: 10.1071/AN15893; TOC Head:

When pre-slaughter welfare is suboptimal, there are also additional costs, besides deaths, which increase the economic losses (Ritter et al. 2009). First of all, bruised carcasses (especially in non-ambulatory pigs) may require extensive trimming, increasing both meat losses and the labour needed on the carcass. Second, slaughtering plants have additional costs for disposing carcasses and increased labour costs to move non-ambulatory pigs humanely. Last, it is well known that fatigued and exhausted pigs are in a metabolic state of acidosis. This metabolic condition may seriously affect pork quality, resulting either in pale, soft, exudative (PSE) or in dark, firm, dry (DFD) meats, depending on when the pig becomes fatigued during the marketing process (Fortin 2002; Carr et al. 2005; Ritter et al. 2009).

A further consistent loss of profit arises from the fact that Italian heavy pigs are intended for high economic-value productions (e.g. Parma ham). According to recent estimates, the average added value in the period 2009-2013 amounted to $0.42 €$ per $\mathrm{kg}$ of fresh Parma ham (De Roest et al. 2014).

\section{Conclusions}

The present study identified some risk factors associated with transport losses in heavy pigs and quantified the economic impact of pre-slaughter losses. Some risk factors were found to be similar to those described for lighter pigs (long journeys, high environmental temperatures), whereas other factors where less well documented in the literature (low density during transport, first batches slaughtered). Overall, the factors highlighted may be helpful in identifying critical points during transport and slaughtering procedures. It is noteworthy that most of the mentioned risk factors would not need specific surveys but could be monitored by analysing the transport and slaughtering data that are routinely collected by slaughterhouses and by the public veterinary services. It is, therefore, hoped that, similarly to what has been proposed for broilers (EC 2007), the evaluation of the outcomes of transport and lairage in terms of swine welfare will be included in the future legislation on the protection of pigs. Last, it could be interesting to conduct further research to assess the economic impact of animal losses along the entire production chain. 


\section{References}

Abbott TA, Guise HJ, Hunter EJ, Penny RHC, Baynes PJ, Easby C (1995) Factors influencing pig deaths during transit: an analysis of drivers' reports. Animal Welfare 4, 29-40.

Averós X, Knowles T, Brown SN, Warriss PD, Gosálvez LF (2008) Factors affecting the mortality of pigs being transported to slaughter. The Veterinary Record 163, 386-390 doi:10.1136/vr.163.13.386.

Barton Gade P, Christensen L (1998) Effect of different stocking densities during transport on welfare and meat quality in Danish slaughter pigs. Meat Science 48, 237-247 doi:10.1016/S0309-1740(97)00098-3.

Barton Gade P, Christensen L, Baltzer M, Valentin Petersen J (2007) Causes of pre-slaughter mortality in Danish slaughter pigs with special emphasis on transport. Animal Welfare 16, 459-470.

Brandt P, Aaslyng MD (2015) Welfare measurements of finishing pigs on the day of slaughter: a review. Meat Science 103, 13-23 doi:10.1016/j.meatsci.2014.12.004.

Brown JA, Samarakone TS, Crowe T, Bergeron R, Widowski T, Correa JA, Faucitano L, Torrey S, Gonyou HW (2011) Temperature and humidity conditions in trucks transporting pigs in two seasons in eastern and western Canada. Transactions of the ASABE 54, 23112318. doi:10.13031/2013.40650

Carr SN, Gooding JP, Rincker PJ, Hamilton DN, Ellis M, Killefer J, Mckeith FK (2005) A survey of pork quality of downer pigs. Journal of Muscle Foods 16, 298-305

doi:10.1111/j.1745-4573.2005.00022.x.

Carr CC, Newman DJ, Rentfrow GK, Keisler DH, Berg EP (2008) Effects of slaughter date, on farm handling, transport stocking density, and time in lairage on digestive tract temperature, serum cortisol concentrations, and pork lean quality of market hogs. The Professional Animal Scientist 24, 208-218. doi:10.1532/S1080-7446(15)30842-1

Christensen L, Barton-Gade P (1999) Temperature profile in double-decker transporters and some consequences for pig welfare during transport. Occasional Publication of the British Society of Animal Science 23, 125-128.

Consortium for Parma Ham (1992) 'Prosciutto di Parma (Parma ham), protected designation of origin. Specifications and dossier.' Available at http://www.prosciuttodiparma.com/pdf/en_UK/Specifications.pdf [Verified December 15, 2015]

De Roest K, Pignedoli S, Belletti G, Menozzi D, Arfini F (2014) 'Italian case study: local and global cured ham chains. EU Projec GLAMUR. (Global and local food chain assessment: a multidimensional performance-based approach).' Available at http://glamur.eu/wpcontent/uploads/2015/04/glamur-wp3-italy-ham-3-cases.pdf [Verified December 2015]

Ellis M, Ritter M (2005) Transport losses: causes and solutions. In 'Allen D. Leman swine conference'. Retrieved from the University of Minnesota Digital Conservancy. Available at http://purl.umn.edu/143195 [Verified December 2015]

European Council (EC) (2005) Council Regulation (EC) No 1/2005 of 22 December 2004 on the protection of animals during transport and related operations and amending Directives 
Publisher: CSIRO; Journal: AN:Animal Production Science

Article Type: research-article; Volume: ; Issue: ; Article ID: AN15893

DOI: 10.1071/AN15893; TOC Head:

64/432/EEC and 93/119/EC and Regulation (EC) No 1255/97. Official Journal of the European Union, L 3, 1-44.

European Council (EC) (2007) Council Directive 2007/43/EC of 28 June 2007 laying down minimum rules for the protection of chickens kept for meat production (text with EEA relevance). Official Journal of the European Union, L 182, 19-28.

Fitzgerald RF, Stalder KJ, Matthews JO, Schultz Kaster CM, Johnson AK (2009) Factors associated with fatigued, injured and dead pig frequency during transport and lairage at a commercial abattoir. Journal of Animal Science 87, 1156-1166 doi:10.2527/jas.2008-1270.

Fortin A (2002) The effect of transport time from the assembly yard to the abattoir and resting time at the abattoir on pork quality. Canadian Journal of Animal Science 82, 141-150 doi:10.4141/A00-097.

García-Celdrán M, Ramis G, Quereda JJ, Armero E (2012) Reduction of transport-induced stress on finishing pigs by increasing lairage time at the slaughter house. Journal of Swine Health and Production 20, 118-122.

Garcia-Diez J, Coelho AC (2014) Causes and factors related to pig carcass condemnation. Veterinarni Medicina 59, 194-201.

Gerritzen MA, Hindle VA, Steinkamp K, Reimert HGM, van der Werf JTN, Marahrens M (2013) The effect of reduced loading density on pig welfare during long distance transport. Animal 7, 1849-1857 doi:10.1017/S1751731113001523.

Geverink NA, Engel B, Lambooij E, Wiegant VM (1996) Observations on behaviour and skin damage of slaughter pigs and treatment during lairage. Applied Animal Behaviour Science 50, 1-13. doi:10.1016/0168-1591(96)01069-6

Gosálvez LF, Averós X, Valdevira JJ, Herranz A (2006) Influence of season, distance and mixed loads on the physical and carcass integrity of pigs transported to slaughter. Meat Science 73, 553-558. doi:10.1016/j.meatsci.2006.02.007

Guàrdia MD, Estany J, Balasch S, Oliver MA, Gispert M, Diestre A (2005) Risk assessment of DFD meat due to pre-slaughter conditions in pigs. Meat Science 70, 709-716 doi:10.1016/j.meatsci.2005.03.007.

Haley C, Dewey CE, Widowski T, Friendship R (2008a) Association between in-transit loss, internal trailer temperature, and distance traveled by Ontario market hogs. Canadian Journal of Animal Science 72, 385-389.

Haley C, Dewey CE, Widowski T, Poljak Z, Friendship R (2008b) Factors associated with intransit losses of market hogs in Ontario in 2001. Canadian Journal of Veterinary Research $72,377-384$.

Huynh TTT, Aarnink AJA, Gerrits WJJ, Heetkamp MJH, Canh TT, Spoolder HAM, Kemp B, Verstegen MWA (2005) Thermal behaviour of growing pigs in response to high temperature and humidity. Applied Animal Behaviour Science 91, 1-16.

doi:10.1016/j.applanim.2004.10.020

Miranda-de la Lama GC, Villarroel M, María GA (2014) Livestock transport from the perspective of the pre-slaughter logistic chain: a review. Meat Science 98, 9-20 doi:10.1016/i.meatsci.2014.04.005. 
Publisher: CSIRO; Journal: AN:Animal Production Science

Article Type: research-article; Volume: ; Issue: ; Article ID: AN15893

DOI: 10.1071/AN15893; TOC Head:

Nannoni E, Widowski T, Torrey S, Fox J, Rocha LM, Gonyou HW, Weschenfelder AV, Crowe T, Martelli G, Faucitano L (2014) Water sprinkling market pigs in a stationary trailer. 2. Effects on selected exsanguination blood parameters and carcass and meat quality variation. Livestock Science 160, 124-131 doi:10.1016/j.livsci.2013.11.022.

Pérez MP, Palacio J, Santolaria MP, Aceña Md C, Chacón G, Verde MT, Calvo JH, Zaragoza MP, Gascón M, García-Belenguer S (2002) Influence of lairage time on some welfare and meat quality parameters in pigs. Veterinary Research 33, 239-250

doi:10.1051/vetres:2002012.

Pilcher CM, Ellis M, Rojo-Gómez A, Curtis SE, Wolter BF, Peterson CM, Peterson BA, Ritter MJ, Brinkmann J (2011) Effects of floor space during transport and journey time on indicators of stress and transport losses of market-weight pigs. Journal of Animal Science 89, 3809-3818 doi:10.2527/jas.2010-3143.

Ritter MJ, Ellis M, Bertelsen CR, Bowman R, Brinkmann J, DeDecker JM, Keffaber KK, Murphy CM, Peterson BA, Schlipf JM, Wolter BF (2007) Effects of distance moved during loading and floor space on the trailer during transport on losses of market weight pigs on arrival at the packing plant. Journal of Animal Science 85, 3454-3461 doi:10.2527/jas.20070232.

Ritter MJ, Ellis M, Bowman R, Brinkmann J, Curtis SE, DeDecker JM, Mendoza O, Murphy CM, Orellana DG, Peterson BA, Rojo A, Schlipf JM, Wolter BF (2008) Effects of season and distance moved during loading on transport losses of market-weight pigs in two commercially available types of trailer. Journal of Animal Science 86, 3137-3145 doi:10.2527/jas.20080873.

Ritter MJ, Ellis M, Berry NL, Curtis SE, Anil L, Berg E, Benjamin M, Butler D, Dewey C, Driessen B, DuBois P, Hill JD, Marchant-Forde JN, Matzat P, McGlone J, Mormede P, Moyer T, Pfalzgraf K, Salak-Johnson J, Siemens M, Sterle J, Stull C, Whiting T, Wolter B, Niekamp SR, Johnson AK (2009) Review: transport losses in market weight pigs: I. A review of definitions, incidence, and economic impact. The Professional Animal Scientist 25, 404414. doi:10.15232/S1080-7446(15)30735-X

Salmi B, Trefan L, Bünger L, Doeschl-Wilson A, Bidanel JP, Terlouw C, Larzul C (2012) Bayesian meta-analysis of the effect of fasting, transport and lairage times on four attributes of pork meat quality. Meat Science 90, 584-598 doi:10.1016/j.meatsci.2011.09.021.

Schrama JW, van der Hel W, Gorssen J, Henken AM, Verstegen MW, Noordhuizen JP (1996) Required thermal thresholds during transport of animals. The Veterinary Quarterly 18, 90-95. doi:10.1080/01652176.1996.9694624

Schwartzkopf-Genswein KS, Faucitano L, Dadgar S, Shand P, González LA, Crowe TG (2012) Road transport of cattle, swine and poultry in North America and its impact on animal welfare, carcass and meat quality: A review. Meat Science 92, 227-243

doi:10.1016/j.meatsci.2012.04.010.

SCIA (2015), Sistema Nazionale per la Raccolta, l'Elaborazione e la Diffusione di Dati Climatici di Interesse Ambientale (Available at http://www.scia.isprambiente.it [Verified December 2015]

Sutherland MA, McDonald A, McGlone JJ (2009) Effects of variations in the environment, length of journey and type of trailer on the mortality and morbidity of pigs being transported to slaughter. The Veterinary Record 165, 13-18. doi:10.1136/vetrec.165.1.13 
Publisher: CSIRO; Journal: AN:Animal Production Science

Article Type: research-article; Volume: ; Issue: ; Article ID: AN15893

DOI: 10.1071/AN15893; TOC Head:

Vitali A, Lana E, Amadori M, Bernabucci U, Nardone A, Lacetera N (2014) Analysis of factors associated with mortality of heavy slaughter pigs during transport and lairage. Journal of Animal Science 92, 5134-5141 doi:10.2527/jas.2014-7670.

Warriss PD (2003) Optimal lairage times and conditions for slaughter pigs: a review. The Veterinary Record 153, 170-176. doi:10.1136/vr.153.6.170

Warriss PD, Brown SN (1994) A survey of mortality in slaughter pigs during transport and lairage. The Veterinary Record 134, 513-515 doi:10.1136/vr.134.20.513.

Werner C, Reiners K, Wicke M (2007) Short as well as long transport duration can affect the welfare of slaughter pigs. Animal Welfare 16, 385-389.

Manuscript received 22 December 2015, accepted 2 August 2016

Fig. 1. Frequency distribution of the absolute number of animals lost pre-slaughter per batch. The percentages are calculated within batches with at least one animal lost pre-slaughter.

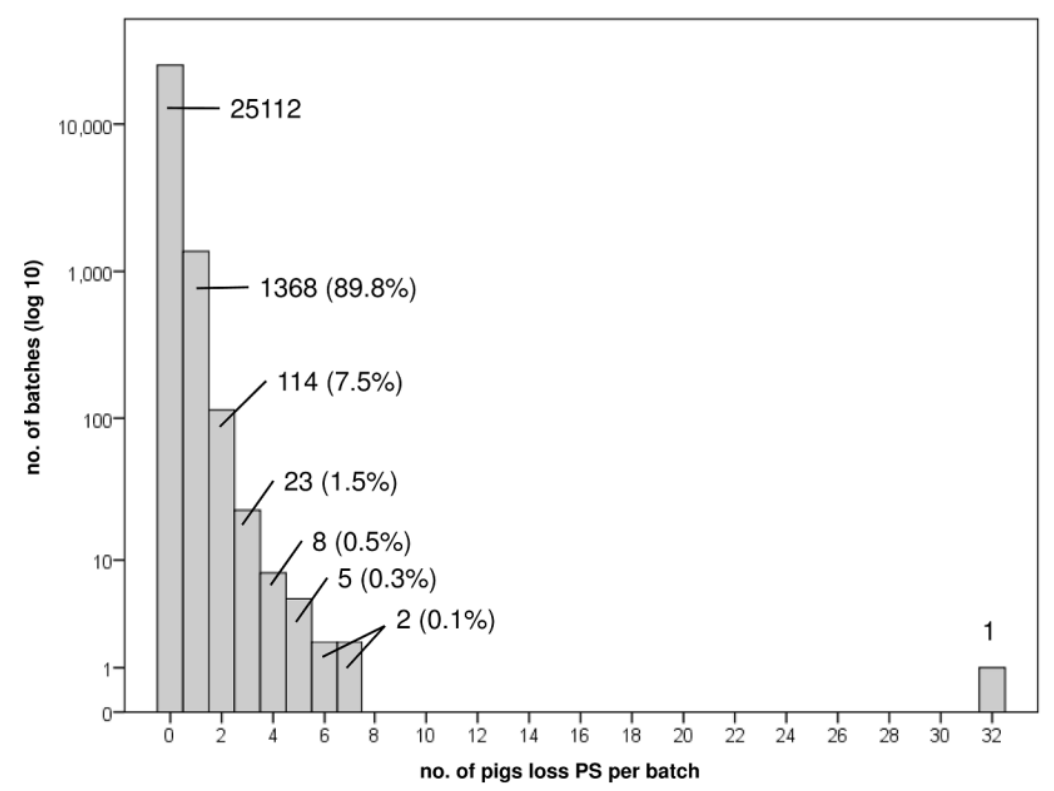


Publisher: CSIRO; Journal: AN:Animal Production Science

Article Type: research-article; Volume: ; Issue: ; Article ID: AN15893

DOI: 10.1071/AN15893; TOC Head:

Fig. 2. Monthly average of the percentage of animals lost pre-slaughter (calculated on the whole number of animals received by the abattoir) during the entire survey.

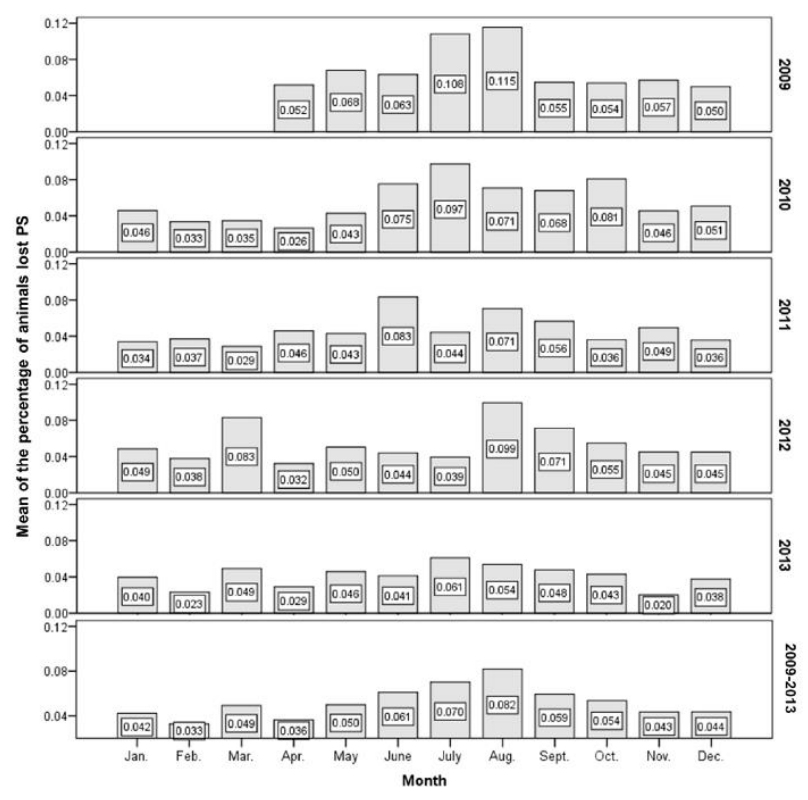


Publisher: CSIRO; Journal: AN:Animal Production Science Article Type: research-article; Volume: ; Issue: ; Article ID: AN15893 DOI: 10.1071/AN15893; TOC Head:

Fig. 3. Proportion of batches with at least one pig lost pre-slaughter by season or by year. Asterisks indicate the presence of significant $(P<0.05)$ seasonal differences within the year.

Season

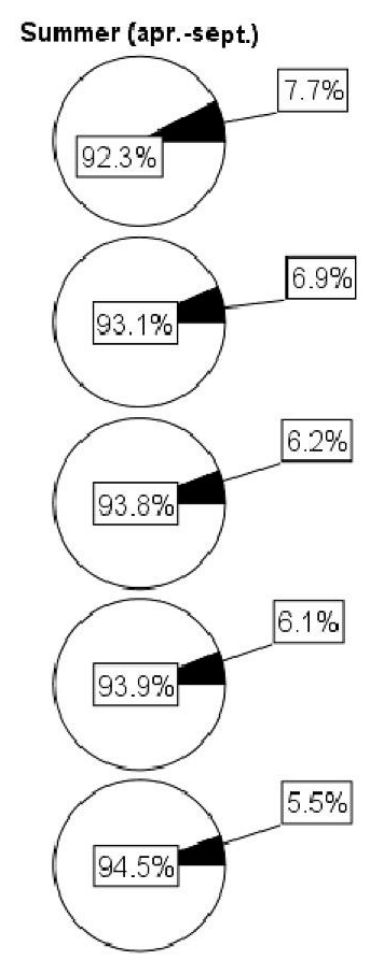

Winter (oct.-mar.)

\section{$6.3 \%$}

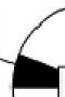

$93.7 \%$
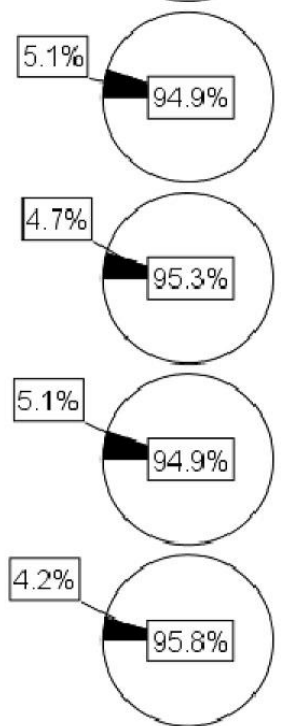

Batch with at least one animal lost PS

ayes

$\square$ no

*

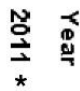

N

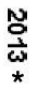


Table 1. Number of batches as a function of season, journey duration, slaughtering order and density during transport

Slaughtering order: a progressive number attributed to every batch on arrival. Lower values correspond to batches of pigs that reached the slaughterhouse on the day before slaughtering, spending the night in lairage and being the first slaughtered on the day after their arrival. Stocking density during transport was dichotomised according to median animal numerosity. Batches of 'high density during transport' were defined as all batches of more than 71 pigs transported

by the same trailer or all batches of more than 140 pigs (in this case a second trailer was used)

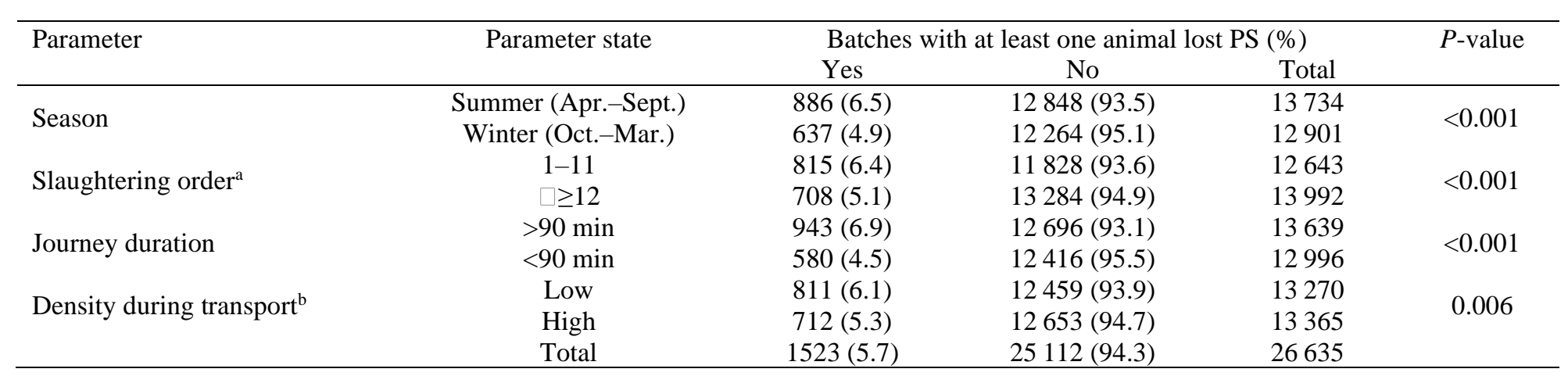


Publisher: CSIRO; Journal: AN:Animal Production Science

Article Type: research-article; Volume: ; Issue: ; Article ID: AN15893

DOI: 10.1071/AN15893; TOC Head:

Table 2. Mean of pigs lost pre-slaughter (PS) and the rate of animals lost PS according to season, median of journey duration, slaughtering order and density during transport (total number of batches: 26 635; number of batches with at least one animal lost PS: 1523; pigs received: 3344 730)

\begin{tabular}{|c|c|c|c|c|c|c|}
\hline Parameter & Parameter state & $\begin{array}{l}\text { No. of pigs lost } \\
\text { PS }\end{array}$ & $\begin{array}{l}\text { Mean of pigs lost PS } \\
\text { per batch }\end{array}$ & $P$-value & $\begin{array}{l}\text { Rate of animals lost PS/1000 animals received } \\
\text { by the abattoir }\end{array}$ & $P$-value \\
\hline \multirow{2}{*}{ Season } & Summer (Apr.-Sept.) & 1048 & 0.08 & $<0.001$ & 0.59 & $<0.001$ \\
\hline & Winter (Oct.-Mar.) & 732 & 0.06 & & 0.45 & \\
\hline \multirow{2}{*}{ Journey duration } & $>90 \min$ & 1122 & 0.08 & $<0.001$ & 0.64 & $<0.001$ \\
\hline & $<90 \mathrm{~min}$ & 658 & 0.05 & & 0.40 & \\
\hline \multirow{2}{*}{ Slaughtering order } & $1-11$ & 937 & 0.07 & $<0.001$ & 0.58 & $<0.001$ \\
\hline & $\geq 12$ & 843 & 0.06 & & 0.47 & \\
\hline \multirow{3}{*}{ Density during transport } & Low & 946 & 0.07 & $<0.01$ & 0.59 & $<0.001$ \\
\hline & High & 834 & 0.06 & & 0.46 & \\
\hline & Total & 1780 & 0.07 & & 0.53 & \\
\hline
\end{tabular}

Table 3. Logistic regression analysis according to season, journey duration, slaughtering order and density during transport

\begin{tabular}{|c|c|c|c|c|c|}
\hline \multirow[t]{2}{*}{ Parameter } & \multirow[t]{2}{*}{ Parameter state } & \multirow[t]{2}{*}{ Odds ratio } & \multicolumn{2}{|c|}{$95 \%$ CI for odds ratio } & \multirow[t]{2}{*}{$P$-value } \\
\hline & & & Lower limit & Upper limit & \\
\hline$\overline{\text { Season }}$ & Summer (Apr.-Sept.) & 1.32 & 1.19 & 1.47 & $<0.001$ \\
\hline Journey duration & $>90 \mathrm{~min}$ & 1.54 & 1.38 & 1.72 & $<0.001$ \\
\hline Slaughtering order & $\geq 12$ & 1.26 & 1.13 & 1.39 & $<0.001$ \\
\hline Density during transport & High & 0.94 & 0.84 & 1.04 & 0.228 \\
\hline Constant & & 11.103 & & & $<0.001$ \\
\hline
\end{tabular}

